\title{
BUSINESS OF UROLOGY
}

\section{Exploring the business of urology: Conflict resolution and negotiation}

\author{
Timothy O. Davies, MD, FRCSC; J. Stuart Oake, MD, MBA, FRCSC; ${ }^{2}$ Darren Beiko, MD, MBA, FRCSC,; \\ Anne-Marie Houle, MD, MBA, FRCSC 4
}

'Department of Surgery, Division of Urology, McMaster University, Hamilton, ON, Canada; ${ }^{2}$ Department of Surgery, Division of Urology, University of Ottawa, Ottawa, 0N, Canada; ${ }^{3}$ Department of Urology, Queen's University, Kingston, ON, Canada; ${ }^{\circ}$ Department of Surgery, Division of Pediatric Urology, Université de Montréal, Montreal, QC, Canada

Cite as: Can Urol Assoc J 2016;10(11-12):379-82. http://dx.doi.org/10.5489/cuaj.4247

\section{Introduction}

Conflicts are a reality of life in society. Indeed, where there are two individuals interacting together, the risk of competing interest or at least the perception of diverging interests exist and, consequently, there is the possibility of an emerging conflict. This is especially true in large organizations in which there still persists a certain degree of hierarchy and, thus, some degree of subordination and control despite new organizational designs favouring flattening of the line of authority and adhocracies. The Canadian healthcare system and its different institutions are no exception: the system represents the combination of a number of different individuals and groups working together with some differing objectives or the perception of diverging goals. Due to the negative connotations associated with conflict and negotiation, many physicians, including urologists, lack formal training in conflict resolution and negotiation. As a result, conflict and negotiation is often avoided when possible. The reality is that urologists are exposed to possible conflicts in their day-to-day lives and conflict resolution and negotiation are, therefore, essential skills. The purpose of this article is to equip urologists with a basic understanding of conflict resolution and provide strategies to resolve conflict and negotiate successfully.

Conflict may be described as a series of phases (Fig. 1). ${ }^{1}$ Conflict begins with a latent phase, with some players having no knowledge of the conflict. Once the conflict has emerged to all involved, it progresses to escalation. Negotiation is a common method to resolve conflict. Conflict is either satisfactorily resolved or it reoccurs and reemerges, cycling yet again. Patients, healthcare professionals, office staff, and hospital administrators are just some of the stakeholders with conflicting agendas. Hospitals and other healthcare environments can be high-stress, with complex organizational structures that generate organizational blur and confusion of roles and responsibilities. These factors increase the risk and severity of conflict (Appendix A). ${ }^{2}$ How we determine our approach and proceed to resolve conflict will determine current and future success.

\section{Styles of conflict resolution}

The intent of our business series is to focus on the day-today business practice issues facing our readership and make them tangible. Below, we categorize the styles of conflict resolution and encourage the reader to apply these styles to your own specific historical conflicts and use the categorization model to lead you through existing and future conflicts/negotiation.

There are five different approaches, or styles, to conflict resolution (Fig. 2). ${ }^{3}$ There is no single "right" approach to all situations; the approach should vary according to the conditions. The different styles can be viewed as a combination of two factors: assertiveness and concern for the other party.

\section{Competing}

Competing occurs when one party is highly assertive and has little concern for the other party. This is successful in those situations with significant differences in power for one party, however, the short-term gain of getting the desired result in the conflict may be mitigated by the negative reactions of those observing this technique. This style is best used when there is an emergency situation, such as a resuscitation, where you are confident in your decision and there is a need for quick and decisive action.

\section{Avoiding}

Avoiding occurs with low assertiveness and low concern, and is ineffective. Since everyone is avoiding the problem, it is not resolved and usually everyone ends up with negative 


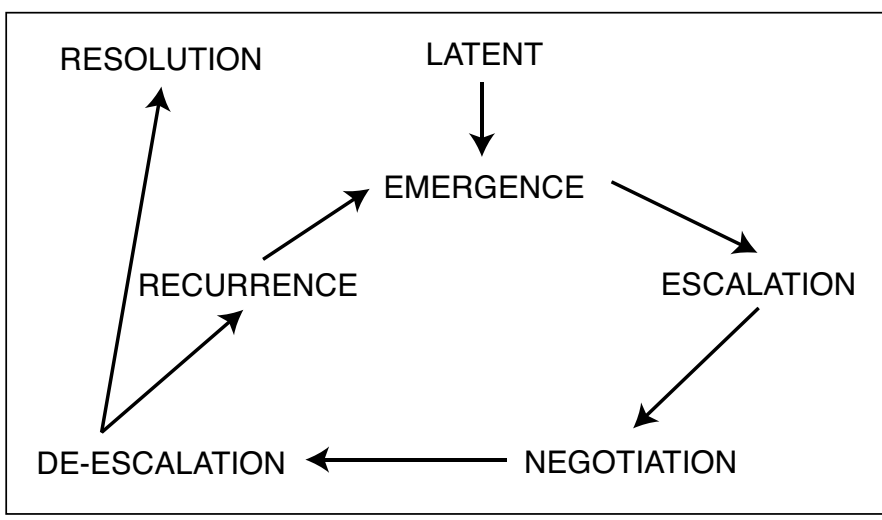

Fig. 1. Stages of conflict adapted from Maung et al. ${ }^{1}$

feelings. In those situations where the outcome is unimportant, this technique would be appropriate.

\section{Collaboration}

Collaboration, with high assertiveness and high concern for the other party, is often seen as the win-win when both parties work together to achieve resolution. It is the most difficult approach in which to succeed, even with equal power between the parties and a long time to achieve resolution. When both parties have highly important positions, this style can allow for a mutually agreeable solution with little or no compromise.

\section{Accommodation}

Accommodation will occur with low assertiveness and high concern for the other. One party will give in and act unselfishly in this style of conflict resolution, which is advantageous when you find you are wrong, or in need of future goodwill.

\section{Compromise}

Compromise will occur when both parties try to find middle ground in a moderate assertive and moderate concern situation. This is a common style of conflict resolution, where a party's loss is offset by a gain in another area. This style is best used in situations when both groups have mutually exclusive goals and the need for resolution is time-sensitive. Negotiation is one method used to resolve conflict.

\section{Negotiation}

Negotiation is, by definition, a process in which two or more parties attempt to come to an agreement. There are two general negotiation strategies: distributive and integrative bargaining. Distributive bargaining involves negotiating over fixed resources. If one party gains, then the other must lose in

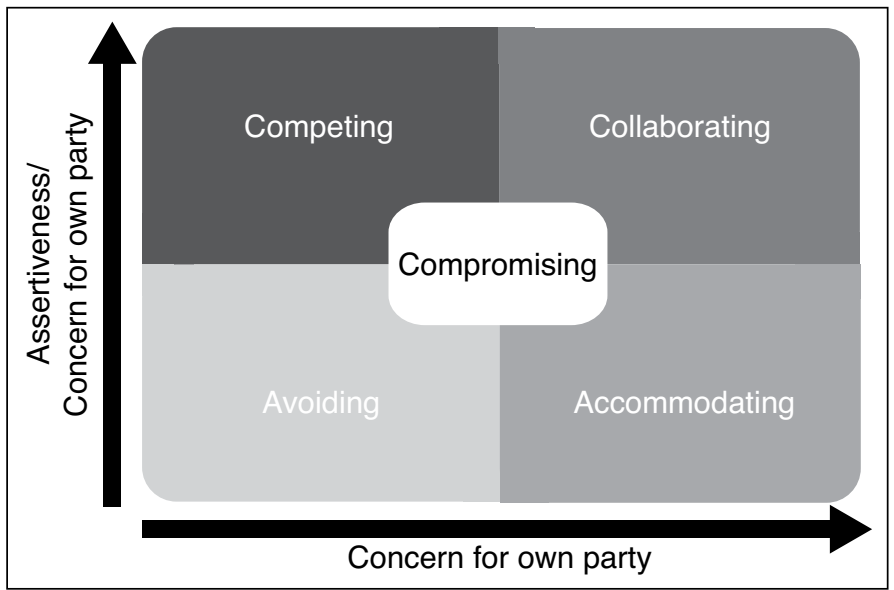

Fig. 2. Thomas-Kilmann model of approaches to conflict resolution adapted from Trippe and Baumoel. ${ }^{3}$

order for total resources to remain unchanged. This strategy is similar to the competing approach of conflict resolution. For example, competing with other services for blocks in the operating room (OR) is direct competition for fixed resources and results in distributive bargaining. Distributive bargaining is a common practice for the urologist who exists in a fixed healthcare budget.

Integrative bargaining is a negotiation strategy that achieves satisfying outcomes for both parties. It is the preferred strategy for most situations, as it results in positive outcomes and good long-term relationships between parties. It may or may not imply new capital availability. An example would be negotiation with another service to exchange an OR day that would facilitate practice management for both parties.

\section{Stages of negotiation ${ }^{4}$}

\section{Preparation}

The preparation process, the most important component of negotiation, is principally intended to prepare your position in a forthcoming negotiation process, the stages of which are below. Knowing what you want, what you need, and what you can give up are the basic tenants of preparation. Preparation for negotiation requires each party to consider the concept of BATNA (best alternative to negotiated agreement) (Appendix B) as a baseline requirement for what you need out of the negotiations. Each party will determine its own goals via the BATNA concept. The term was coined by Fisher and Ury and defined as the standard against which all other proposals should be measured. In other words, the BATNA is the point at which a party would walk away from the negotiation. If the negotiation will result in a worse outcome than the BATNA, then it is in their best interest to walk away and choose the BATNA. It is a level below which 
you will not consider. It is considered a safety net to the possibility of failed negotiations, but it must be considered in the preparation process.

\section{Remaining stages}

1. Exchanging information: Non-confrontational explanation of the parties' positions and all relevant information is put forward.

2. Bargaining: This is the stage most people think of when they use the word negotiation. The goal is for both parties to feel satisfied at the end of this stage.

3. Closing and commitment: This stage is the formalizing of the agreed-upon agreement from the previous stage. This stage may be long or short, depending on the specific parties and circumstance.

\section{Practical approach to negotiation (Appendix C)}

The classic text, "Getting to Yes: Negotiating Agreement Without Giving $\ln ^{\prime \prime} 5$ provides an excellent framework to guide negotiation. It supports principle negotiation, an approach that should increase the chances of a win-win resolution to conflict. The authors use a specific method to assume a hard position on the issue or problem and a soft position on the people involved in the conflict to maximize successful negotiation. When reading the framework provided below, consider the specifics of the medical environment in which you practice; for example, egos can be powerful and obstructive. Highly trained individuals tend to have high expectations. Consider the following example when reading the framework below: You are Party 1, a physician interested in building a new program at a hospital in which you practice that requires a capital investment from the hospital. Party 2 is hospital administration, whose portfolio will oversee your new program.

1. Separate the people from the problem - Don't let emotions get involved in defining the conflict between the two parties. Be clear on perception, recognize emotions, communicate clearly, and listen closely. Empathize: understand the situation as it is seen by the other party

2. Focus on interests, not positions - Explore the underlying reasons for the positions that each group has brought to the table. The deeper examination of the issue may clarify what the groups really want, not just their superficial positions. Find common ground to build on.

3. Generate option for mutual gain - Take time to generate possible solutions that benefit both groups and do so together. Brainstorm ideas while looking for mutual gain.

4. Insist on using objective criteria - Use mutually agreedupon and objective criteria for evaluation of the solutions. If the standards or procedures are fair, then it is more likely to come to a mutually satisfactory solution. There are other practical tactics for managing healthcare conflict to consider. Do not rush. Slowing down will allow for gathering all the relevant information before acting on it. Also, ensure the directly related parties are the only parties involved in the conflict resolution, simplifying and removing any distractions. If a committee is involved, clarify roles and expectations of each member of the team. Avoid escalating the process to a "high level" to make sure to address the issue at the appropriate level. Don't use avoidant strategy as the default resolution mechanism; deal with issues directly when possible. Despite using all of the mentioned strategies, the conflict may not be resolved through negotiation and an impasse results. At those times, alternative methods are needed to reach a settlement.

\section{Alternative dispute resolution}

Negotiation and conflict management may result in a stalemate and an alternative dispute mechanism may need to be employed. ${ }^{6}$ This may play out in a protracted court battle or an agreed-upon process. Mediation is a process that is organized by a neutral third party, but cannot impose a solution if none is reached. Arbitration is the use of a third party to resolve a conflict with the power to impose a resolution if none is reached. Arbitration has more risk for the parties involved since the third party has the power to impose their own solution, which may or may not be favourable.

Conflict is often viewed as a negative condition with its load of disadvantages and costs (Appendix D), ${ }^{7}$ but it can also provide a positive experience and an opportunity for the identification of a problem and the consolidation of the relation between individuals/groups participating at finding a shared solution. Growth and positive change are achievable with good leadership and a rational approach to conflict resolution.

Competing interests: Dr. Davies has been an advisor for Allergan, Boston Scientific, and Pfizer; and has received grants/honoraria from Allergan, Astellas, Boston Scientific, and Pfizer. Dr. Oake has been an advisor for and has received honoraria from Boston Scientific. Dr. Beiko has received sponsored travel, lodging, and honoraria from Cook Medical. Dr. Houle reports no competing personal or financial interests.

This paper has been peer-reviewed.

\section{References}

1. Maung AA, Toevs $\mathrm{CC}$, Kayser JB, et al. Conflict management teams in the intensive care unit: A concise definitive review. J Trauma Acute Care Surg 2015;79:314-20. http://dx.doi.org/10.1097/ TA. 0000000000000728

2. Mayer BS. The dynamics of conflict resolution. A practitioner's guide. San Francisco: Jossey-Bass 2008.

3. Trippe B, Baumoel D. Beyond the Thomas-Kilmann model: Into extreme conflict. Negotiation J 2015;31: 89-103. http://dx.doi.org/10.1111/nejo.12084

4. Shell GR. Bargaining for Advantage. Penguin; 2006. 
Davies et al.

5. Fisher R, Ury WL, Patton B. Getting to Yes. Penguin; 2011.

6. Sohn DH, Bal BS. Medical malpractice reform: The role of alternative dispute resolution. Clin Orthop Relat Res 2012;470:1370-8. http://dx.doi.org/10.1007/s11999-011-2206-2

7. Simpao AF. Conflict management in the health care workplace. Physician Exec 2013; 39: 54-8.
Correspondence: Dr. Timothy Davies, Department of Surgery, Division of Urology, McMaster University, Hamilton, 0N, Canada; tdavies@mcmaster.ca

\begin{tabular}{ll}
\hline Appendix A. Bernard Mayer's 5 sources of conflict \\
\hline 1. Communication & $\begin{array}{l}\text { Imperfection of the sending or receiving of } \\
\text { a message }\end{array}$ \\
2. Emotions & $\begin{array}{l}\text { Anger and jealousy can start/add to the } \\
\text { conflict }\end{array}$ \\
3. Values & $\begin{array}{l}\text { Different values between individuals can } \\
\text { lead to conflict } \\
\text { External factors making the structure of the } \\
\text { conflict (e.g., physical work environment, } \\
\text { resources, etc.) } \\
\text { Background of the parties involved in the } \\
\text { conflict }\end{array}$ \\
\hline
\end{tabular}

\begin{tabular}{|c|c|}
\hline \multicolumn{2}{|c|}{ Appendix B. Memory aid to help prepare for a negotiation } \\
\hline \multicolumn{2}{|c|}{ Explicit interests/stakes } \\
\hline Party A & Party B \\
\hline 1. & 1. \\
\hline 2. & 2. \\
\hline 3. & 3. \\
\hline \multicolumn{2}{|c|}{ Implicit interests/stakes } \\
\hline Party A & Party B \\
\hline 1. & 1. \\
\hline 2. & 2. \\
\hline 3. & 3. \\
\hline \multicolumn{2}{|c|}{ Objectives of the negotiation } \\
\hline Party A & Party B \\
\hline 1. & 1. \\
\hline 2. & 2. \\
\hline 3. & 3. \\
\hline \multicolumn{2}{|c|}{ Zones of possible agreement } \\
\hline \multicolumn{2}{|c|}{ Nice to have: } \\
\hline \multicolumn{2}{|c|}{ Should have: } \\
\hline \multicolumn{2}{|c|}{ Must have: } \\
\hline \multicolumn{2}{|c|}{ Best alternatives } \\
\hline Party A & Party B \\
\hline 1. & 1. \\
\hline 2. & 2. \\
\hline 3. & 3. \\
\hline \multicolumn{2}{|c|}{ Worst-case scenarios } \\
\hline Party A & Party B \\
\hline 1. & 1. \\
\hline 2. & 2. \\
\hline 3. & 3. \\
\hline
\end{tabular}

\begin{tabular}{l}
\hline Appendix C. Practical approach to negotiation \\
\hline 1. Separate the people from the problem \\
2. Focus on interests, not positions \\
3. Generate options for mutual gain \\
4. Insist on using objective criteria \\
\hline
\end{tabular}

\section{Appendix D. Costs of conflict}

\section{Direct}

Litigation costs

Management productivity

losses

Turnover staffing costs

Disability or stress leave claims

Sabotage, theft, damage

\section{Indirect}

Diminished team morale

Decreased patient satisfaction

Decreased organizational reputation and cohesion Emotional costs of those involved

Synergy lost, collaboration lost 